\title{
Naming ability changes in physiological and pathological aging
}

\author{
Maria Cotelli ${ }^{1}$, Rosa Manenti ${ }^{1}$, Michela Brambilla ${ }^{1}$, Orazio Zanetti ${ }^{1}$ and \\ Carlo Miniussi ${ }^{1,2}$ \\ 1 IRCCS Centro San Giovanni di Dio Fatebenefratelli, Brescia, Italy \\ ${ }^{2}$ Department of Clinical and Experimental Sciences, National Neuroscience Institute, University of Brescia, Brescia, Italy
}

Edited by:

Hari S. Sharma, Uppsala University,

Sweden

Reviewed by:

Giovanni Tosi, University of Modena and Reggio Emilia, Italy

Madeleine Le Grevès, Uppsala University,

Sweden

Dimitar Maslarov, First Multiprofile

Hospital for Active Treatment, Bulgaria

${ }^{*}$ Correspondence:

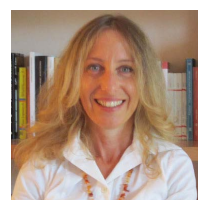

Maria Cotelli is Head of

Neuropsychology Laboratory at IRCCS

Saint John of God Clinical Research

Centre. After her M.Sc. in Psychology in Padua, she received her Ph.D. in Cognitive Science from the University of Turin. Her primary research interests concern linguistic aspects of aphasia, brain plasticity, with a particular focus on application of neuroimaging and neurophysiological methods to the study of cognitive functions in patients and in neurologically unimpaired individuals

and neurorehabilitation.

mcotelli@fatebenefratelli.it

Over the last two decades, age-related anatomical and functional brain changes have been characterized by evidence acquired primarily by means of non-invasive functional neuroimaging. These functional changes are believed to favor positive reorganization driven by adaptations to system changes as compensation for cognitive decline. These functional modifications have been linked to residual brain plasticity mechanisms, suggesting that all areas of the brain remain plastic during physiological and pathological aging. A technique that can be used to investigate changes in physiological and pathological aging is non-invasive brain stimulation (NIBS). The present paper reviews studies that have applied NIBS in younger and older adults and in patients with dementia to track changes in the cerebral areas involved in a language task (naming). The results of this research suggest that the left frontal and temporal areas are crucial during naming. Moreover, it is suggested that in older adults and patients with dementia, the right prefrontal cortex is also engaged during naming tasks, and naming performance correlates with age and/or the degree of the pathological process. Potential theories underlying the bilateral involvement of the prefrontal cortex are discussed, and the relationship between the bilateral engagement of the prefrontal cortex and the age or degree of pathology is explored.

Keywords: language, brain stimulation, HAROLD, plasticity, cognition

One of the primary areas of investigation in neuroscience is age-related brain changes and the associations between these changes and changes in cognitive (e.g., language) function. Progress regarding the study of physiological and pathological brain aging achieved over the last two decades has provided strong evidence of neurophysiological correlates of cognitive and behavioral changes associated with aging.

For example, studies at the neuronal level have demonstrated that dopaminergic decline and gray matter atrophy are both correlated with specific cognitive changes in older adults (Brody, 1955; Coleman and Flood, 1987; West et al., 1994; Small et al., 2002; Resnick et al., 2003; Sowell et al., 2003; Burke and Barnes, 2006; Kramer et al., 2007). In addition, it has been clearly demonstrated that processing speed, memory, and executive functions depend on the "well-being" of several neuronal substrates (Kennedy and Raz, 2009). Structural imaging results have also demonstrated widespread gray and white matter tissue atrophy, which largely occurs in the frontal cortex (e.g., Raz et al., 2005).

Based on evidence primarily acquired via noninvasive functional neuroimaging, four principal hypotheses have been postulated to explain the relationship between age-related neuronal 
Age-related brain changes The studies of physiological and pathological brain aging achieved over the last two decades has provided strong evidence of neurophysiological correlates of cognitive and behavioral changes associated with aging.

Neural strategies

The STAC presents a reunified vision of the dynamic brain changes that occur in response to naturally occurring functional alterations across the life span (Park and Reuter-Lorenz, 2009). activity changes and cognitive performance (Reuter-Lorenz and Park, 2010). First, an overactivation of some cortical areas and a reduction in the hemispheric asymmetry of activation has been documented in older adults as compared to younger adults during cognitive task execution (Grady et al., 1992; Backman et al., 1997; Cabeza, 2002; Park and Reuter-Lorenz, 2009). This frontal lobe overactivation has been reported in episodic memory, working memory, and perceptual tasks (Grady et al., 1995, 1998; Cabeza, 2002; Grady, 2008). By reviewing age-related differences in prefrontal cortex activity during working memory and episodic memory tasks, Rajah and D'Esposito (2005) reported both age-related decreases and increases of activity in specific prefrontal regions.

Second, a loss of regional specialization or declining specificity, referred to as dedifferentiation, has been hypothesized to occur in older adults (Reinert, 1970; Lindenberger and Baltes, 1994; Chee et al., 2006; Voss et al., 2008). Ventralvisual activity in older adults is characterized by the dedifferentiation of responses to different stimuli categories, such as faces and/or houses (Park et al., 2004). In addition, Goh et al. (2010) reported that the dedifferentiation of neural responses in older adults is associated with a reduction of the distinctiveness of within-category representations in the ventral-visual cortex.

Third, frontal compensation has been investigated in older adults because higher prefrontal activation is more prevalent in older adults than in younger adults during several cognitive tasks (Cabeza et al., 2003; Gutchess et al., 2005; Davis et al., 2008; Heuninckx et al., 2008; Eyler et al., 2011; Cabeza and Dennis, in press). Neuroimaging studies have revealed an age-related reduction in occipito-temporal activity coupled with an increase in frontal activity, a pattern referred to as the posterior-anterior shift in aging (Davis et al., 2008).

Fourth, the default network theory postulates that the activity in several regions of the default mode network is altered during the execution of several cognitive tasks; these regions includes the medial prefrontal cortex and the medial and lateral parietal cortex (Raichle et al., 2001; Lustig et al., 2003; Reuter-Lorenz and Lustig, 2005; Persson et al., 2007; Miller et al., 2008; Mevel et al., 2011). Furthermore, the activity in the major components of the default mode network remains stable in healthy, older individuals, whereas the activity in a number of discrete cortical areas located in the prefrontal, temporal, and occipital regions changes over time (BeasonHeld et al., 2009). Indeed, all of these hypotheses largely overlap, but all of them at least partially underline the cerebral tissue's ability to change its structure and function continuously in response to environmental demands.

All of these physiological-aging-induced structural and functional changes have been linked to residual brain plasticity to counteract neural loss (Jancke, 2009). It has therefore been suggested that neural plasticity facilitates alternative "neural strategies" to maintain an adequate level of cognitive performance (Greenwood, 2007; Zollig and Eschen, 2009). The scaffolding theory of aging and cognition (STAC; Park and ReuterLorenz, 2009) presents a reunified vision of the dynamic brain changes that occur in response to naturally occurring functional alterations across the life span. According to the STAC, the brain responds to physiological aging by forging alternative brain circuitry (scaffolds); although they are less efficient, this process permits the individual to maintain a high level of cognitive functioning. Consequently, brain scaffolding would result in a pattern of overactivation and eventually reduced lateralization, which is consistent with the results of previous neuroimaging studies; however, this pattern of overactivation would be present in the frontal cortex and in the parietal, medio-temporal, and occipital regions (Reuter-Lorenz and Park, 2010).

\section{NEURAL CORRELATES OF OBJECT AND ACTION NAMING}

Language skills are examples of cognitive abilities that change during aging. Human language is a complex behavior that involves multiple processes (Pulvermuller, 2003). Similar to other functional abilities, language processing has been shown to be lateralized to brain regions of the left hemisphere. One important process in the constellation of language skills is naming. Evidence from both lesion and imaging studies suggests a central role of the left prefrontal, temporal, and parietal areas during naming, although some involvement differences exist for object (noun) versus action (verb) naming (Daniele et al., 1994; Perani et al., 1999; Price et al., 2005). Naming is an ability that shows adaptation during aging; however, few studies have investigated how the engagement of these areas changes during the performance of naming tasks in older adults.

In brain-damaged patients with acquired aphasia, selective category-specific deficits have been described for grammatical word classes, such as for nouns and verbs (Miceli et al., 1984). Several clinical observations have suggested that different cerebral areas are involved in noun and verb processing. Ample evidence suggests that aphasic patients may be selectively impaired in object naming but not in action naming or vice 
versa (Miceli et al., 1984; Baxter and Warrington, 1985; McCarthy and Warrington, 1985; Miceli, 1988; Miceli and Caramazza, 1988; Caramazza and Hillis, 1991; Miozzo et al., 1994). Patients with a selective disorder for object naming typically have lesions localized to the left temporal lobe; conversely, a selective impairment in action naming has been associated with larger lesions, which typically extend to the left frontal cortex (Daniele et al., 1994).

In conclusion, various studies have convincingly demonstrated that the lexical system is organized according to grammatical class. Furthermore, Damasio and Damasio (1992) suggested that mediation systems for verbs may be located in frontal and parietal sites.

These results were considered to support the findings of focal lesion studies that suggested the frontal lobe plays a central role in verb processing (Cappa and Perani, 2003; Shapiro and Caramazza, 2003a,b; Silveri and Ciccarelli, 2007). Functional brain imaging studies involving patients and neurotypical participants have provided evidence for the selective recruitment of brain areas associated with noun and verb processing (Perani et al., 1999; Shapiro et al., 2006). Specifically, actions apparently evoke stronger activation than objects in the bilateral posterior middle temporal cortex, in the left temporo-parietal junction, and in the left frontal cortex (Liljestrom et al., 2008). Nevertheless, recent studies have suggested that the relationship between the grammatical class and the related pattern of brain activation is not clear-cut and must be more thoroughly investigated (Pulvermuller et al., 1999, 2012; Crepaldi et al., 2011; Vigliocco et al., 2011).

\section{NAMING IN PATHOLOGICAL AGING}

The study of degenerative conditions has also provided converging evidence; specifically, a severe impairment in action naming has been identified in patients with frontal dementia (Cappa et al., 1998). The diagnostic label of frontotemporal dementia (FTD) encompasses a number of heterogeneous clinical presentations, in which different patterns of neuropsychological impairment in linguistic processing, executive function, and action organization reflect the location of the underlying pathology. Cotelli et al. (2006a) reported that action naming is impaired in comparison to object naming in patients with FTD, and some differences exist between different FTD variants. A severe action naming disorder has been observed in patients with Non-fluent Primary Progressive Aphasia (NfPPA), Progressive Supranuclear Palsy (PSP), and Corticobasal Degeneration (CBD), while no significant difference in object and action naming was demonstrated in Semantic Dementia (SD; a subtype of FTD associated with higher temporal atrophy localization). Overall, these findings confirm the crucial role of the frontal cortex in action naming but not in object naming. Furthermore, the observation of a severe impairment in verb retrieval in patients with NfPPA is not unexpected. This variant is associated with a clinical presentation similar to Broca's aphasia that reflects prominent pathological involvement of the anterior language areas (Hillis et al., 2004). The results were less expected in the case of PSP and, in particular, of CBD because a verb-naming disorder in PSP had originally been reported (Daniele et al., 1994; Bak et al., 2001).

The finding of a severe verb production deficit in two conditions that are clinically characterized by a prominent movement disorder implicates a link between action-related language and action representation (Hauk et al., 2004; Tettamanti et al., 2005). In another report, Cotelli et al. (2007) described a particularly severe impairment in action naming associated with Parkinson disease (PD). PD is a neurodegenerative process characterized by several motor and cognitive clinical manifestations for which effective, mechanism based treatments remain elusive (RodriguezOroz et al., 2009). Compared to the controls, PD patients showed a deficit both in action and object naming. In addition, PD patients were significantly more impaired in action naming than in object naming; there was a significant positive correlation between the severity of the action naming impairment (and the degree of action-object naming dissociation) and the severity of the visual and verbal long-term memory impairments, which are the classical features of PD neuropsychological impairment. The severity of the verb retrieval impairment in $\mathrm{PD}$ patients may be a consequence of dopamine depletion in the striatum, which would disrupt the function of the subcortical prefrontal networks (Alexander et al., 1986). These results may be due to an initial executive impairment (Muslimovic et al., 2005; Zgaljardic et al., 2006) or a specific language dysfunction. Recently, an fMRI study concluded that frontal-motor dysfunction in PD affects tasks that require a complicated action-related search (Peran et al., 2009), suggesting the presence of a linguistic dysfunction in these patients. Further investigation of these conditions may provide additional insight into the relationships between the localization of cortical involvement, the pattern of lexical impairment, and the specific features of high-order motor dysfunction experienced. 
Age-related decline in object and action naming

Several studies have demonstrated an age-related decline in object and action naming suggesting that word retrieval declines in healthy aging and in pathological aging.
These findings are particularly interesting given the brain modifications that are associated with physiological aging. When interpreting the dissociation of action and object processing in older adults, one should consider the role of the frontal cortex and the dynamic alteration of this area due to aging. These changes are reflected in functional compensation processes; if the STAC theory is correct, these compensation processes should be associated with specific changes in naming performance.

\section{NAMING AND HEALTHY AGING}

Some important domains of cognitive ability decline with age, including processing speed, memory, reasoning, and language (Salthouse, 2010). In general, the effect of normal aging on language is characterized by a complex pattern. Performance on comprehension and vocabulary knowledge is well maintained (Burke and Shafto, 2008; Shafto et al., 2009; Tyler et al., 2010), while word finding performance declines (Albert et al., 1988; Goral et al., 2007; Wierenga et al., 2008). A progressive reduction in lexical retrieval performance has been well-documented in older adults (Nicholas et al., 1985; Bowles et al., 1987; Albert et al., 1988; Au et al., 1995; Barresi et al., 2000; Mackay et al., 2002; Morrison et al., 2003; Connor et al., 2004; Mortensen et al., 2006). Unlike the retrieval of word meaning, which appears to be preserved and even enhanced with aging (Verhaeghen, 2003; Goral et al., 2007), the ability to retrieve the sound or phonology of words seems to decline in older adults. People of all ages struggle to identify the correct word on a daily basis. This difficulty, referred to as tip-ofthe-tongue phenomenon, is a temporary inability to access a word's phonology following a successful activation of semantic information (Cross and Burke, 2004; Schwartz and Metcalfe, 2011). Nevertheless, the frequency of tip-of-the-tongue experiences significantly increases with aging, and older adults report the inability to produce well-known words as one of the most annoying cognitive "symptoms" they experience (Burke and Shafto, 2004; Shafto et al., 2007). Recent neuroimaging findings have demonstrated that agerelated word retrieval difficulties are associated with atrophy in linguistic areas and are correlated with white matter integrity across a broad range of regions that have been implicated in language production (Stamatakis et al., 2005, 2011). The frequency of tip-of-the-tongue episodes has been shown to be positively correlated with adult age and negatively correlated with gray matter density in the left insula (Shafto et al., 2007, 2009). Several other factors have been demonstrated to contribute to this decline, including gender (Ross et al., 1995), education (Goral et al., 2007), and general health status (Albert et al., 2009).

One of the primary paradigms used to evaluate word finding skills in the normal aging population has been the picture-naming test. Picturenaming is a complex task and a variety of issues could contribute to poor performance on this task, including visual problems, semantic deficits or grammatical deficits, loss of word forms, or impaired access to phonological forms (Price et al., 2005; DeLeon et al., 2007). Picture-naming is known to engage large and distinct neural networks (Price et al., 2005; Cotelli et al., 2006a) that are differentially required for the different processes underlying picture-naming (DeLeon et al., 2007; Liljestrom et al., 2008), and these networks have been demonstrated to undergo modification during aging (Wierenga et al., 2008).

Several studies have demonstrated an agerelated decline in object and action naming (Goodglass, 1980; Nicholas et al., 1985; LaBarge et al., 1986; Ardilla and Rosselli, 1989; Feyereisen, 1997), suggesting that word retrieval, rather than lexical and semantic knowledge, declines in healthy aging (Goral et al., 2007). Some differences in object and action naming have been demonstrated in elderly individuals with controversial results (Nicholas et al., 1985; Barresi et al., 2000).

Differences in the performances of younger and older adult participants on a picture-naming task have also been related to a slowing of processing speed with age (Cotelli et al., 2010). In this respect, a number of studies have provided data consistent with the hypothesis that older adults are slower than younger adults when performing picture-naming tasks (Thomas et al., 1977; Mitchell, 1989; Morrison et al., 2003). Several studies have compared latencies between object and action naming in younger and older adult individuals, and they revealed that action naming is more difficult than object naming, both in terms of accuracy and in terms of latencies (Szekely et al., 2005; Druks et al., 2006).

Figure 1 reflects data collected in our laboratory and illustrates action and object naming correctness trends in younger and older adults and in Alzheimer disease (AD) participants at a different impairment stages (Cappa et al., 2002; Cotelli et al., 2006b, 2008, 2010). We performed an ANOVA (groups: younger, older, mild AD, severe $\mathrm{AD}$ ) within-subjects (stimulus: object, action). This analysis revealed a significant effect between the stimulus and group $[F(3,40)=8.052$, $p=0.0003]$. Post hoc analyses (Bonferroni) were conducted. As shown in Figure 1, small differences in action naming performance were found 
Non-Invasive Brain Stimulation (NIBS)

Non-invasive brain stimulation techniques for modulating cortical activity include TMS and tDCS. Both TMS and tDCS can transiently influence behavior by altering spontaneous neuronal activity, which may have facilitatory or inhibitory effects.

This review underlines the presence of a facilitatory effect on naming following right or left DLPFC rTMS stimulation in older adults. This bilateral frontal effect may be attributed to the presence of a compensatory mechanism that is based on the recruitment of right hemisphere resources to maintain task performance.

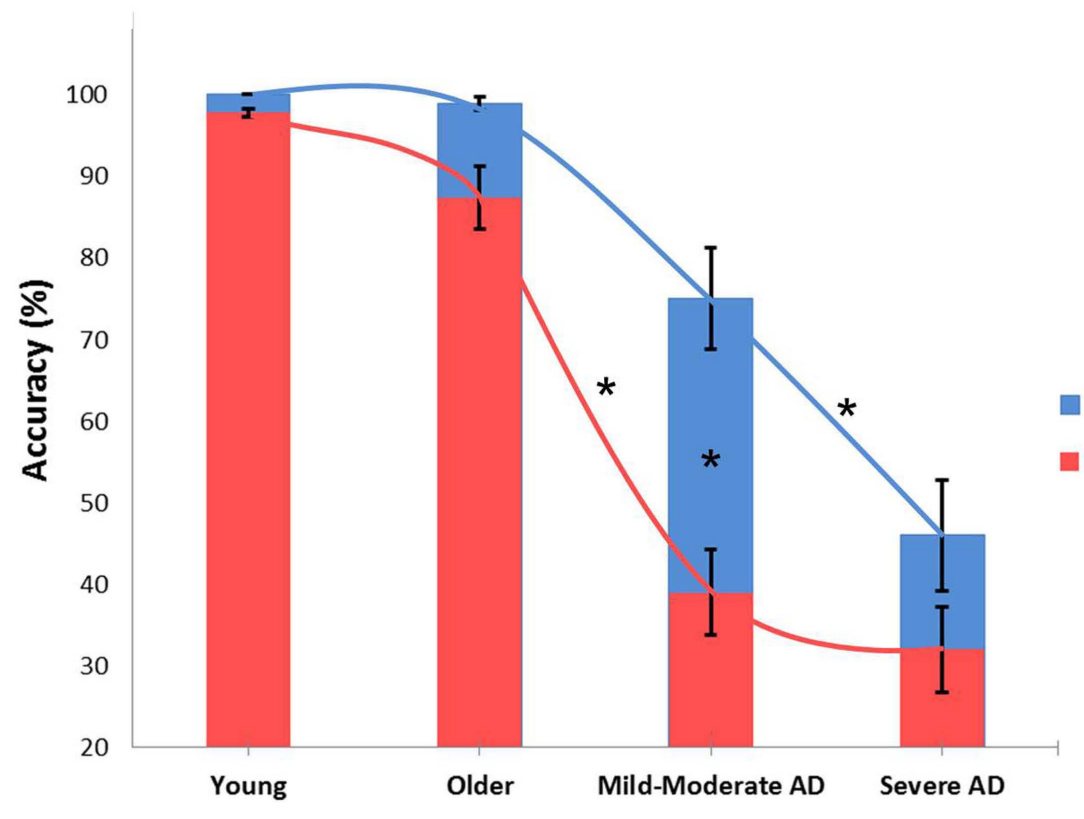

FIGURE 1 |Accuracy performance for object and action naming in young adults (9 participants; Cappa et al., 2002), older adults (13 participants; Cotelli et al., 2010), Alzheimer's Disease patients at mild to moderate stages of cognitive impairment (12 participants) and Alzheimer's Disease patients at severe stages (12 participants; Cotelli et al., 2008). Asterisks indicate significant effects $(p<0.05)$. Mild-moderate AD patients demonstrated significantly worse action naming accuracy than older adults and better performance in object naming than severe AD. Finally, a significant difference between action and object naming performance was only evident in the mild to moderate AD group. Errors bars indicate mean standard error.

between younger and older adult participants, but the differences were not statistically significant (Cappa et al., 2002; Cotelli et al., 2010). Moreover, patients in the early stages of $\mathrm{AD}$ (mild to moderate) demonstrated dramatically reduced action naming accuracy $(p=0.000004)$, with a minor and insignificant decrease $(p=0.08)$ in object naming performance compared to older adults. Finally, AD patients in the advanced stages of cognitive decline (severe) also demonstrated a drastic decrease in object naming accuracy ( $p=0.014$; Cotelli et al., 2006b, 2008). These data suggest that there a continuum in the decline of picture-naming ability exists, and it correlates with physiological and pathological aging. A significant difference between action and object naming performance (i.e., higher accuracy for objects) was only evident in the mild AD group $(p=0.000001)$. To investigate the possible effects of participant characteristics on naming performance, we performed a correlational analysis between age and naming abilities in all four groups, and we performed a similar analysis between mini mental state examination (i.e., cognitive impairment) and naming abilities in older participants and AD patients. Significant correlations between age and both object and action naming abilities (object naming:
$R=-0.52, p<0.001$; action naming: $R=-0.65$, $p<0.001$ ) indicate a progressive decrease of naming abilities during aging. Furthermore, the significant correlations between mini mental state examination and both object and action naming accuracies (object naming: $R=0.83$, $p<0.001$; action naming: $R=0.81, p<0.001$ ) indicate that a progressive decrease of naming abilities is linked to cognitive deterioration (see Figure 2). Identifying the neural correlates of these picture-naming performance changes would further increase our understanding of the processes underling aging, and picture-naming may be important as a tool to evaluate the degree of aging-associated cognitive deterioration.

\section{NON-INVASIVE BRAIN STIMULATION STUDIES ON NAMING IN YOUNGER ADULTS, OLDER ADULTS, AND DEMENTIA PATIENTS}

Since the beginning of the century, important technological advancements have occurred, which have allowed us to study the structures and mechanisms underlying cognitive functions in the human brain. One such development has been the introduction of non-invasive brain stimulation (NIBS). NIBS approaches aim to induce changes in brain activity, which can lead to a wide range 


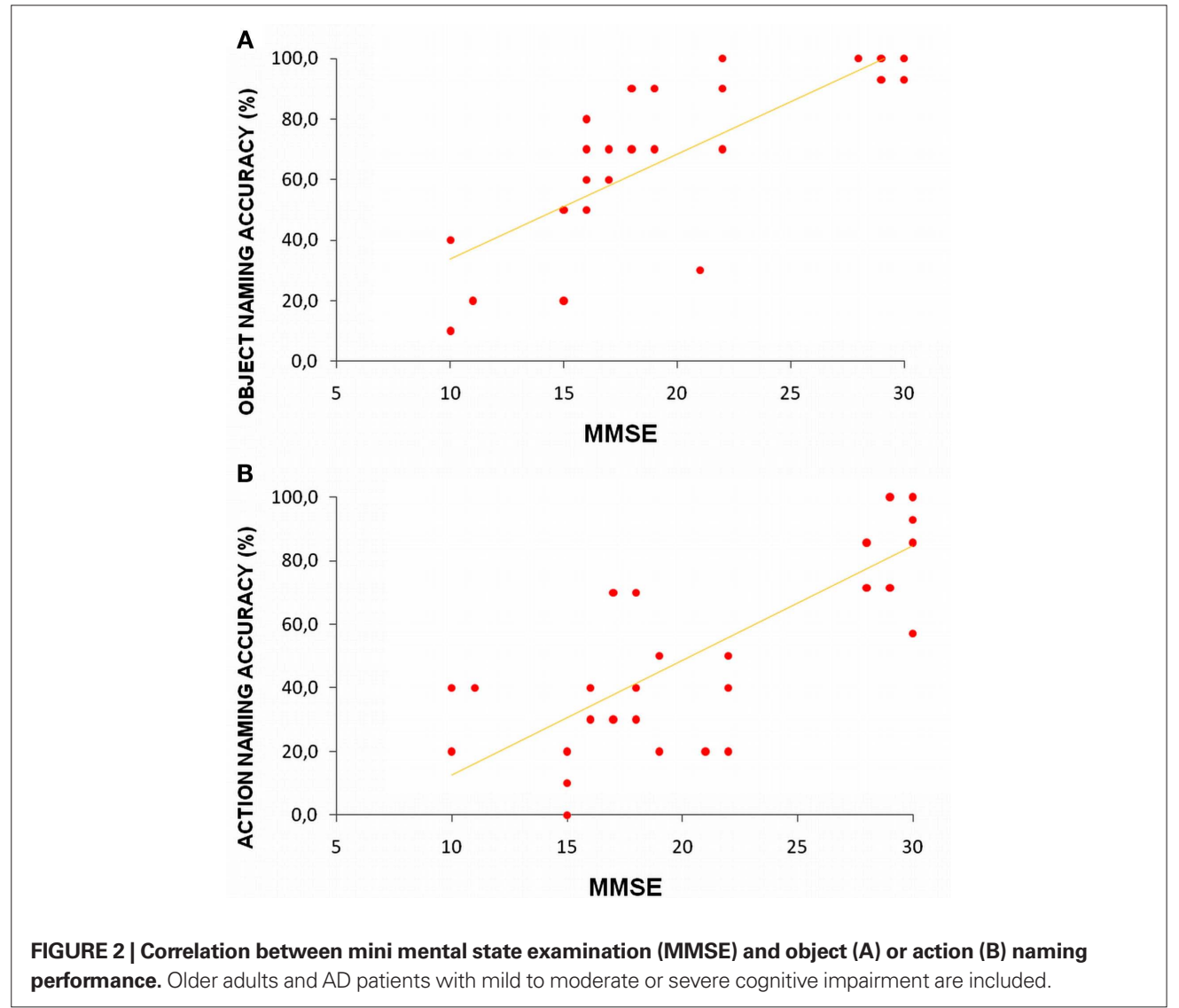

of behavioral alterations (e.g., Nitsche et al., 2008; Sandrini et al., 2011). NIBS techniques include transcranial magnetic stimulation (TMS) and transcranial direct current stimulation (tDCS). TMS and tDCS transiently influence behavior by altering neuronal activity through different mechanisms (Miniussi et al., 2010) which may have facilitative or inhibitory effects. The relevance of NIBS to cognitive neuroscience is primarily derived from its ability to transiently probe the functions of the stimulated cortical area/ network, whereas its relevance to neurorehabilitation is derived from its ability to modulate cortical excitability (Cotelli et al., 2011a,b, 2012; Miniussi and Rossini, 2011). Several recent studies involving young adult participants, have reported improvements in picture-naming abilities following TMS administration (Table 1). Topper et al. (1998) applied single pulse TMS over one of three locations (left Wernicke's area, its right contralateral homologous or the left motor cortex) at different timings during an object naming task. The results demonstrated that TMS over Wernicke's area induced shorter reaction times (RTs) only if the TMS pulse was delivered 500-1000 ms prior to picture presentation. Subsequently, Mottaghy et al. (1999, 2006) and Sparing et al.
(2001) confirmed the involvement of Wernicke's area in object naming using single pulse TMS and repetitive TMS (rTMS). Subsequent studies demonstrated that the temporal pole (Pobric et al. 2007) and middle temporal gyrus (Acheson et al., 2011) also play important roles in object naming. The inferior frontal cortex (in particular, Broca's area) has also been shown to be relevant during object naming. By applying three-pulse TMS over Broca's area, Schuhmann et al. (2009) showed an increase in RTs, and the same result was observed by Chouinard et al., (2009) using rTMS. Recently, Schuhmann et al. (2012) performed a chronometry study, and by delivering TMS at different intervals, they demonstrated that the temporal and inferior frontal areas are critical to naming ability. Schuhmann et al. (2012) demonstrated that the left middle temporal gyrus becomes functionally relevant $225 \mathrm{~ms}$ after picture onset; this result is followed by Broca's area at $300 \mathrm{~ms}$ and Wernicke's area at $400 \mathrm{~ms}$. These results clarified and summarized the role of the inferior frontal cortex and temporal areas during naming.

The involvement of the dorsolateral prefrontal cortex (DLPFC) in naming tasks has also been evaluated. Cappa et al. (2002) reported selective facilitation of action (but not object) naming 


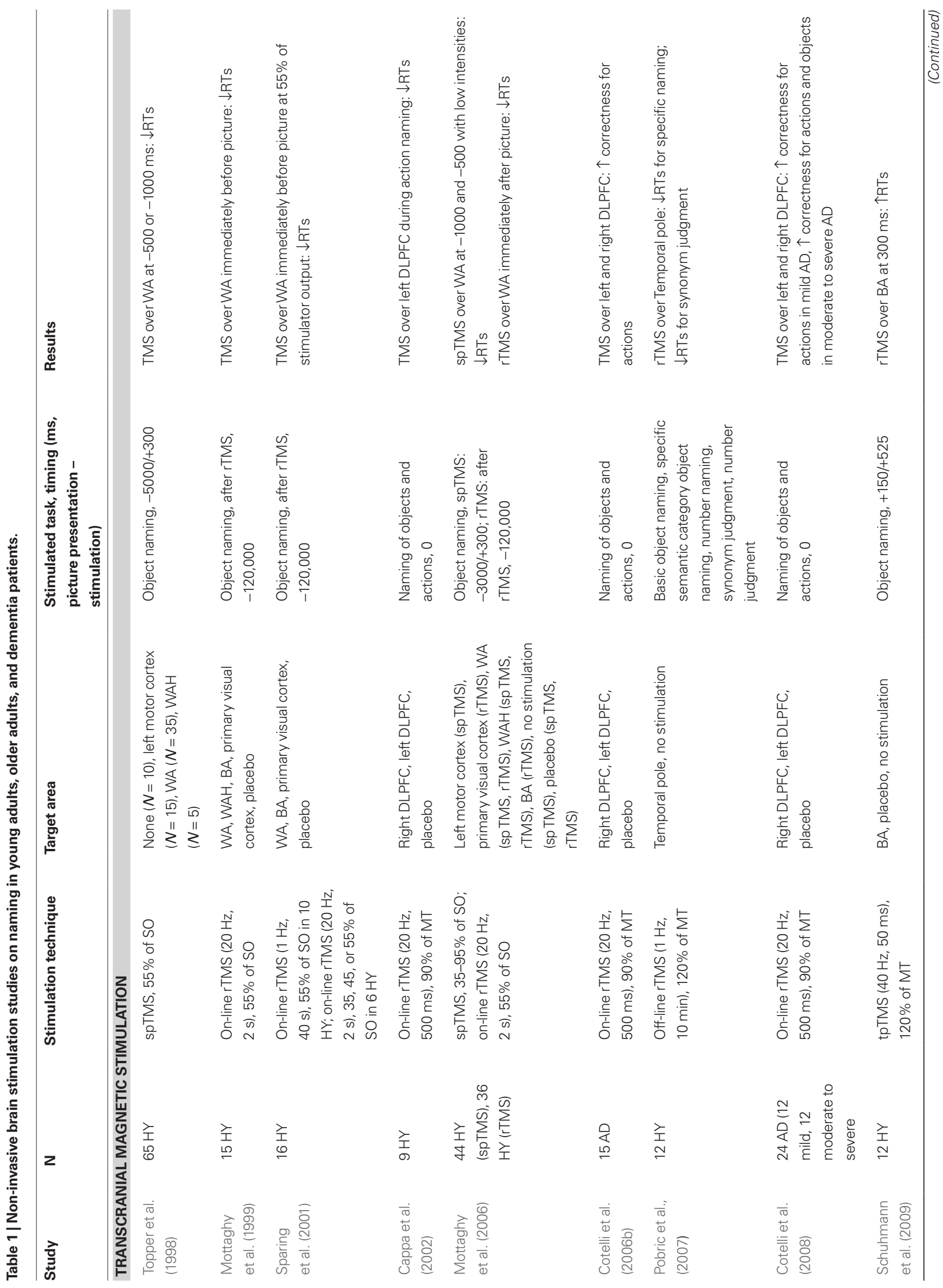




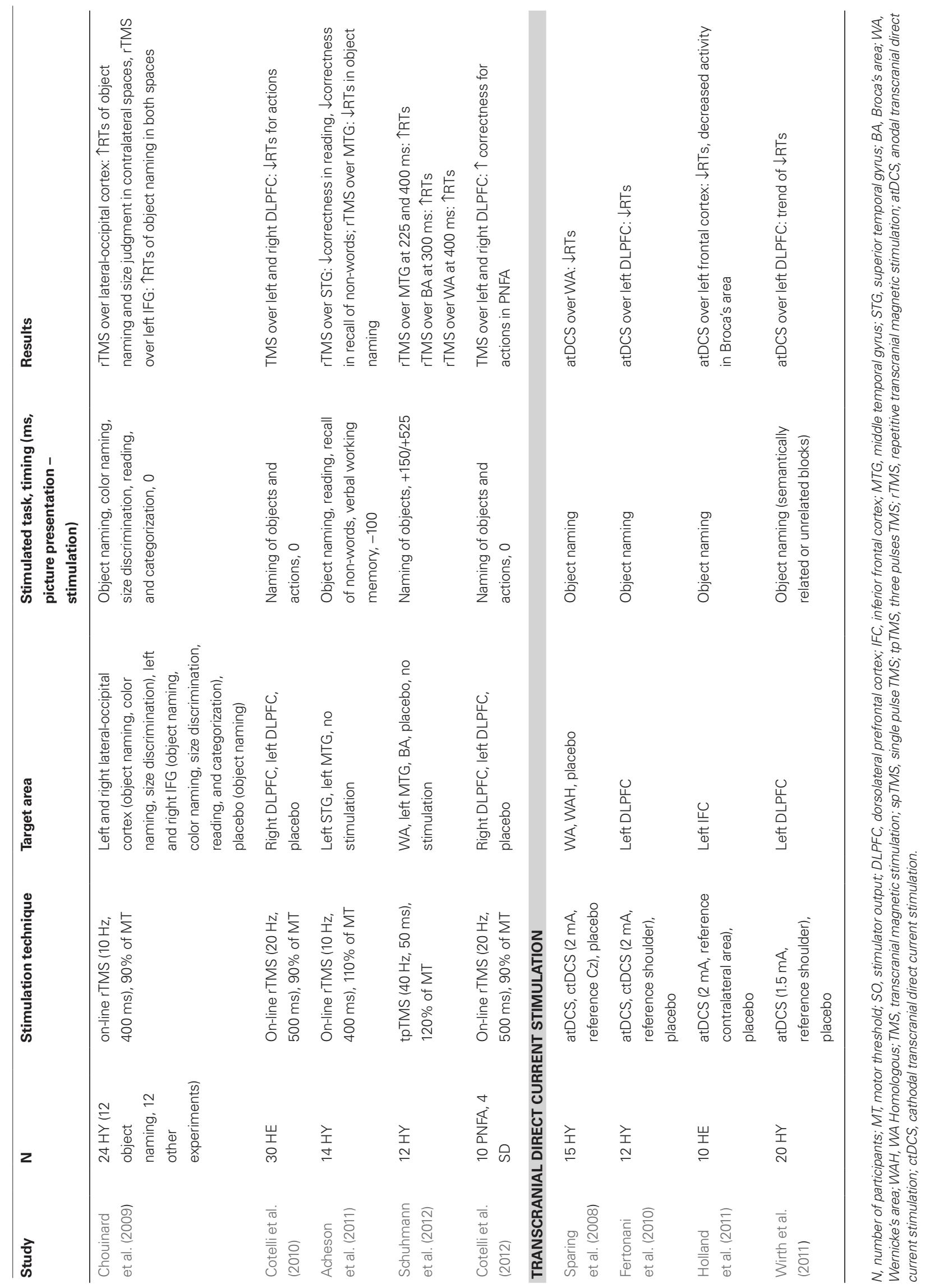


when young adults received rTMS to the left DLPFC; the verbal reaction times (vRTs) were shortened following rTMS compared to sham (i.e., placebo) stimulation. A unique study investigated action and object naming in older adults (Cotelli et al., 2010) by applying rTMS over the left or right DLPFC. Cotelli et al. (2010) observed that although the rTMS effect in younger adults (Cappa et al., 2002) was limited to left-sided stimulation, facilitation in older adults was bilateral, which is demonstrated in Figure 3.

Functional neuroimaging studies have revealed that older adults tend to recruit regions of the contralateral hemisphere in addition to regions of the specialized hemisphere when performing cognitive tasks (Grady et al., 1998; D’Esposito et al., 1999; Grady, 2000; Rypma and D’Esposito, 2000; Cabeza et al., 2002; Logan et al., 2002; Stebbins et al., 2002; Wierenga et al., 2008). According to the frontal compensation hypothesis, the presence of a facilitation effect following right or left DLPFC stimulation in older adults may be attributed to the presence of a compensatory mechanism based on the recruitment of right hemispheric resources to maintain task performance despite the possible reduction in neural efficacy of a distributed naming network. A shift from unilateral to bilateral engagement is consistent with Cabeza's (Cabeza, 2002; Cabeza et al., 2002) model of hemispheric asymmetry reduction in older adults (HAROLD). The HAROLD hypothesis proposes that bilateral activation increases with age. Although evidence from many cognitive tasks supports the HAROLD hypothesis (Grady et al., 1995; Rossi et al., 2001; Cabeza, 2002), the importance of these lateralization reductions remains unclear. Only one NIBS study (Manenti et al., 2011) that tested episodic memory abilities in elderly individuals supports the frontal compensation hypothesis. Manenti et al. (2011) highlighted the presence of a reduction in asymmetry that was specific to older adults who performed better on memory tests (similar to younger adults) in comparison to older adults whose performances were worse on memory tests (for a review, see Manenti et al., 2012).

Cotelli et al. (2010) demonstrated that both right and left DLPFC stimulation during action naming led to shorter vRTs (Figure 3 ) and suggested that these data provide evidence of agingassociated cortical plasticity. The right hemisphere becomes functionally relevant during naming to compensate for the aging-related decreased efficiency of the left hemisphere. Further studies are needed to more thoroughly understand the functional significance of this bilateral recruitment.
Cotelli and collaborators (Cotelli et al., 2006b; Miniussi and Rossini, 2011) applied rTMS in AD patients and found that stimulation of the DLPFC improves naming performance in $\mathrm{AD}$ patients at both early (Cotelli et al., 2006b) and advanced stages (Cotelli et al., 2008) of cognitive decline. Compared to the sham stimulation condition, the correctness scores of the AD patients increased following left and right rTMS to DLPFC. Moreover, in patients in the early stages of cognitive decline, rTMS improved action naming performance only, while rTMS improved both action- and object-naming performance in patients at more advanced stages of cognitive decline.

Although several studies have been conducted using TMS during naming tasks, only three studies have used tDCS to study naming processes in younger or older adults. Sparing et al. (2008) verified the role of Wernicke's area in object naming by demonstrating that anodal tDCS over this area induced shorter vRTs in young adults. The other two studies involving young adult participants demonstrated the DLPFC's role during naming, revealing shorter vRTs during anodal tDCS compared to cathodal tDCS or placebo stimulation (Fertonani et al., 2010; Wirth et al., 2011). A unique fMRI-tDCS study investigated the role of the inferior frontal cortex during object naming in older adults (Holland et al., 2011) and demonstrated that the left inferior frontal cortex is critical to naming ability; vRTs were shortened during anodal tDCS compared to during the placebo condition. Furthermore, faster naming responses correlated with a decreased blood-oxygen-level-dependent signal in Broca's area, which reinforced the importance of this region within the normal naming network.

In summary, several NIBS studies have highlighted frontal and temporal areas that are causally involved in naming in younger adults, whereas only two studies have investigated naming in older adults. A few studies have utilized this technique to examine age-related pathologies and have demonstrated increased performance following DLPFC stimulation. Overall, these results suggest that it would be interesting to use NIBS to modulate performance, to study functional adaptation in physiological aging and eventually to attempt to reduce cognitive deficits in pathological brain aging.

\section{CONCLUSION}

In this article, we reviewed studies that utilized NIBS to study language processing in younger and older adults and in dementia patients. In particular, we focused on a study of naming in older participants using TMS (Cotelli et al., 2010). 


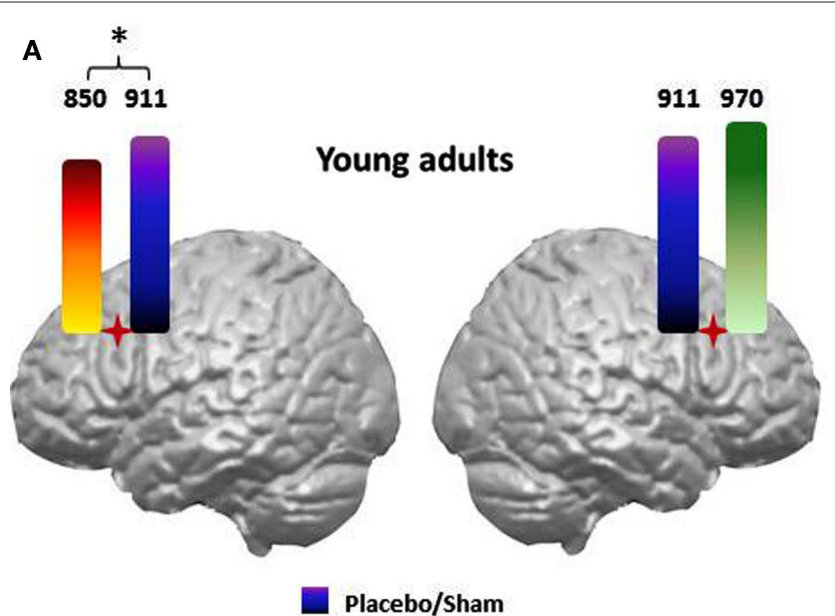

Placebo/Sham

Right stimulation

B

Left stimulation
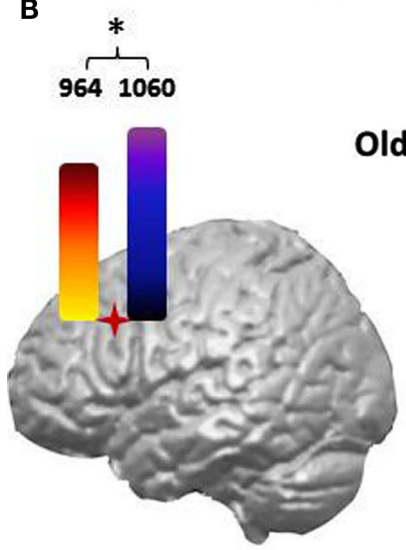

Old adults

FIGURE 3 |Verbal reaction times (vRTs) achieved during an action naming task in younger (A) and older adults (B) following right and left dorsolateral prefrontal cortex (DLPFC) stimulation when compared to sham/placebo stimulation. The facilitatory effect induced by left or right DLPFC stimulation is plotted separately for action and object stimuli. In the older participants, the vRTs for actions were consistently faster during real left or right DLPFC stimulation than during sham stimulation. No significant differences between real and sham stimulation were observed for object naming.

The age-related changes that were observed in this TMS naming study are consistent with other neuroimaging discoveries and theories of cognitive aging. This study underlines the presence of a facilitatory effect on naming following right or left DLPFC stimulation in older adults; this result is in contrast to the unilateral (i.e., left) effect that was previously observed in young adults. This bilateral frontal effect may be attributed to the presence of a compensatory mechanism that is based on the recruitment of right hemisphere resources to maintain task performance (Cabeza, 2002; Cabeza et al., 2002). The same mechanisms could underlie the increased naming accuracy induced by both left and right DLPFC TMS in neurodegenerative patients (Cotelli et al., 2006b, 2008, 2012).

\section{FUTURE DIRECTIONS}

Because NIBS techniques were shown to modify cortical activity, these methods may assist in the evaluation of naming functional changes at the cortical level in aging subjects. Based on its facilitatory behavioral effects in normal and pathological subjects, NIBS could also be used to facilitate "scaffolding" (the manifestation of compensatory networks) in all types of individuals who experience naming difficulties.

\section{ACKNOWLEDGMENTS}

This work was supported by a grant from the Alzheimer's Association (NIRG-11-205099). We would like to thank Dr. Clarissa Ferrari for her assistance with the statistical analyses. 


\section{REFERENCES}

Acheson, D. J., Hamidi, M., Binder, J. R., and Postle, B. R. (2011). A common neural substrate for language production and verbal working memory. J. Cogn. Neurosci. 23, 1358-1367.

Albert, M. L., Spiro, A. III, Sayers, K. J., Cohen, J. A., Brady, C. B., Goral, M., and Obler, L. K. (2009). Effects of health status on word finding in aging. J. Am. Geriatr. Soc. 57, 2300-2305.

Albert, M. S., Heller, H. S., and Milberg, W. (1988). Changes in naming ability with age. Psychol. Aging 3, 173-178.

Alexander, G. E., DeLong, M. R., and Strick, P. L. (1986). Parallel organization of functionally segregated circuits linking basal ganglia and cortex. Annu. Rev. Neurosci. 9, 357-381.

Ardilla, A., and Rosselli, M. (1989). Neuropsychological characteristics of normal aging. Dev. Neuropsychol. 5, 307-320.

Au, R., Joung, P., Nicholas, M., Obler, L. K., Kass, R., and Albert, M. L. (1995). Naming ability across the adult life span. Aging Cogn. 2, 300-311.

Backman, L., Almkvist, O., Anderson, J., Nordberg, A., Winblad, B., Reineck, R., and Langström, B (1997). Brain activation in young and older adults during implicit and explicit retrieval. J. Cogn. Neurosci. 9, 378-391.

Bak, T. H., O’Donovan, D. G., Xuereb, J. H., Boniface, S., and Hodges, J. R. (2001). Selective impairment of verb processing associated with pathological changes in Brodmann areas 44 and 45 in the motor neurone diseasedementia-aphasia syndrome. Brain 124, 103-120.

Barresi, B. A., Nicholas, M., Connor, L. T., Obler, L., and Albert, M. L. (2000). Semantic degradation, and lexical access in age-related naming failures. Aging Neuropsychol. Cogn. 7, 169-178.

Baxter, D. M., and Warrington, E. K. (1985). Category specific phonological dysgraphia. Neuropsychologia 23, 653-666.

Beason-Held, L. L., Kraut, M. A., Resnick, S.M. (2009). Stability of default-mode network activity in the aging brain. Brain Imaging Behav. 3, 123-131.

Bowles, N. L., Obler, L. K., and Albert, M. L. (1987). Naming errors in healthy aging and dementia of the Alzheimer type. Cortex 23, 519-524.

Brody, H. (1955). Organization of the cerebral cortex. III. A study of aging in the human cerebral cortex. J. Comp. Neurol. 102, 511-516.

Burke, D. M., and Shafto, M. A. (2004). Aging and language production. Curr. Dir. Psychol. Sci. 13, 21-24.

Burke, D. M., and Shafto, M. A. (2008). Language and Aging. New York: Psychological Press.
Burke, S. N., and Barnes, C. A. (2006). Neural plasticity in the ageing brain. Nat. Rev. Neurosci. 7, 30-40.

Cabeza, R. (2002). Hemispheric asymmetry reduction in older adults: the HAROLD model. Psychol. Aging 17, 85-100.

Cabeza, R., Anderson, N. D., Locantore, J. K., and McIntosh, A. R. (2002). Aging gracefully: compensatory brain activity in high-performing older adults. Neuroimage 17, 1394-1402.

Cabeza, R., and Dennis, N. A. (in press) "Frontal lobes and aging: deterioration and compensation," in Principles of Frontal Lobe Function, eds D. T. Stuss and R. T. Knight (New York: Oxford University Press).

Cabeza, R., Locantore, J. K., and Anderson, N.D. (2003). Lateralization of prefrontal activity during episodic memory retrieval: evidence for the production-monitoring hypothesis. J. Cogn. Neurosci. 15, 249-259.

Cappa, S. F., Binetti, G., Pezzini, A. Padovani, A., Rozzini, L., and Trabucchi, M. (1998). Object and action naming in Alzheimer's disease and frontotemporal dementia [see comment]. Neurology 50, 351-355.

Cappa, S. F., and Perani, D. (2003). The neural correlates of noun and verb processing. J. Neurolinguistics 16, 183-189.

Cappa, S. F., Sandrini, M., Rossini, P. M. Sosta, K., and Miniussi, C. (2002). The role of the left frontal lobe in action naming: rTMS evidence. Neurology 59, 720-723.

Caramazza, A., and Hillis, A. E. (1991). Lexical organization of nouns and verbs in the brain. Nature 349 , 788-790.

Chee, M. W., Goh, J. O., Venkatraman, V., Tan, J. C., Gutchess, A., Sutton, B. Hebrank, A., Leshikar, E., and Park, D. (2006). Age-related changes in object processing and contextual binding revealed using $\mathrm{fMR}$ adaptation. $J$. Cogn. Neurosci. 18, 495-507.

Chouinard, P. A., Whitwell, R. L., and Goodale, M. A. (2009). The lateraloccipital and the inferior-frontal cortex play different roles during the naming of visually presented objects. Hum. Brain Mapp. 30, 3851-3864.

Coleman, P. D., and Flood, D. G. (1987). Neuron numbers and dendritic extent in normal aging and Alzheimer's disease. Neurobiol. Aging 8, 521-545.

Connor, L. T., Spiro, A. III, Obler, L. K., and Albert, M. L. (2004). Change in object naming ability during adulthood. J. Gerontol. B Psychol. Sci. Soc. Sci. 59, P203-P209.

Cotelli, M., Borroni, B., Manenti, R., Alberici, A., Calabria, M., Agosti, C., Arévalo, A., Ginex, V., Ortelli, P., Binetti, G., Zanetti, O., Padovani, A., and Cappa, S. F. (2006a). Action and object naming in frontotemporal dementia, progressive supranuclear palsy, and corticobasal degeneration. Neuropsychology 20, 558-565.

Cotelli, M., Manenti, R., Cappa, S. F., Geroldi, C., Zanetti, O., Rossini, P. M., and Miniussi, C. (2006b). Effect of transcranial magnetic stimulation on action naming in patients with Alzheimer disease. Arch. Neurol. 63, 1602-1604.

Cotelli, M., Borroni, B., Manenti, R. Zanetti, M., Arevalo, A., Cappa, S. F., and Padovani, A. (2007). Action and object naming in Parkinson's disease without dementia. Eur. J. Neurol. 14 632-637.

Cotelli, M., Calabria, M., Manenti, R., Rosini, S., Zanetti, O., Cappa, S. F. and Miniussi, C. (2011a). Improved language performance in Alzheimer disease following brain stimulation. J. Neurol. Neurosurg. Psychiatr. 82, 794-797.

Cotelli, M., Fertonani, A., Miozzo, A., Rosini, S., Manenti, R., Padovani A., Ansaldo, A. I., Cappa, S. F., and Miniussi, C. (2011b). Anomia training and brain stimulation in chronic aphasia. Neuropsychol. Rehabil. 21, 717-741.

Cotelli, M., Manenti, R., Alberici, A., Brambilla, M., Cosseddu, M. Zanetti, O., Miozzo, A., Padovani, A. Miniussi, C., and Borroni, B. (2012). Prefrontal cortex rTMS enhances action naming in progressive nonfluent aphasia. Eur. J. Neurol. doi: 10.1111/j.1468-1331.2012.03699.x

Cotelli, M., Manenti, R., Cappa, S. F., Zanetti, O., and Miniussi, C. (2008) Transcranial magnetic stimulation improves naming in Alzheimer disease patients at different stages of cognitive decline. Eur. J. Neurol. 15, 1286-1292.

Cotelli, M., Manenti, R., Rosini, S. Calabria, M., Brambilla, M., Bisiacchi, P. S., Zanetti, O., Miniussi, C. (2010) Action and object naming in physiological aging: an rTMS study. Front Aging Neurosci. 2:151. doi: 10.3389/ fnagi.2010.00151

Crepaldi, D., Berlingeri, M., Paulesu, E. and Luzzatti, C. (2011). A place for nouns and a place for verbs? A critical review of neurocognitive data on grammatical-class effects. Brain Lang 116, 33-49.

Cross, E. S., and Burke, D. M. (2004) Do alternative names block young and older adults' retrieval of proper names? Brain Lang. 89, 174-181.

Damasio, A. R., and Damasio, H. (1992). Brain and language. Sci. Am. 267, 88-95.

Daniele, A., Giustolisi, L., Silveri, M. C., Colosimo, C., and Gainotti, G. (1994). Evidence for a possible neuroana- tomical basis for lexical processing of nouns and verbs. Neuropsychologia 32, 1325-1341.

Davis, S. W., Dennis, N. A., Daselaar, S. M., Fleck, M. S., and Cabeza, R. (2008). Que PASA? The posterioranterior shift in aging. Cereb. Cortex 18, 1201-1209.

DeLeon, J., Gottesman, R. F., Kleinman, J. T., Newhart, M., Davis, C., HeidlerGary, J., Lee, A., and Hillis, A. E. (2007). Neural regions essential for distinct cognitive processes underlying picture naming. Brain 130 , 1408-1422.

D’Esposito, M., Zarahn, E., Aguirre, G. K. and Rypma, B. (1999). The effect of normal aging on the coupling of neural activity to the bold hemodynamic response. Neuroimage 10, 6-14.

Druks, J., Masterson, J., Kopelman, M., Clare, L., Rose, A., and Rai, G. (2006). Is action naming better preserved (than object naming) in Alzheimer's disease and why should we ask? Brain Lang. 98, 332-340.

Eyler, L. T., Sherzai, A., Kaup, A. R., and Jeste, D. V. (2011). A review of functional brain imaging correlates of successful cognitive aging. Biol. Psychiatry 70, 115-122.

Fertonani, A., Rosini, S., Cotelli, M. Rossini, P.M., and Miniussi, C. (2010). Naming facilitation induced by transcranial direct current stimulation. Behav. Brain Res. 208, 311-318.

Feyereisen, P. (1997). A meta-analytic procedure shows an age-related decline in picture naming: comments on Goulet, Ska, and Kahn (1994). J. Speech Lang. Hear. Res. 40, 1328-1333.

Goh, J. O., Suzuki, A., and Park, D. C. (2010). Reduced neural selectivity increases $\mathrm{fMRI}$ adaptation with age during face discrimination. Neuroimage 51, 336-344.

Goodglass, H. (1980) "Naming disorders in aphasia and aging," in Language and Comunication in the Ederly, eds L. K. Obler and M. L. Albert (Toronto: Lexington Books), 37-45.

Goral, M., Spiro, A. III, Albert, M., Obler, L. K., and Connor, L. T. (2007). Change in lexical-retrieval skills in adulthood. Ment. Lex. 2, 215-240.

Grady, C. L. (2000). Functional brain imaging and age-related changes in cognition. Biol. Psychol. 54, 259-281.

Grady, C. L. (2008). Cognitive neuroscience of aging. Ann. N. Y. Acad. Sci. 1124, 127-144.

Grady, C. L., Haxby, J. V., Horwitz, B., Schapiro, M. B., Rapoport, S., Ungerleider, L. G., Mishkin, M., Carson, R. E., and Herscovitch, P. (1992). Dissociation of object and spatial vision in human extrastriate cortex: a age-related changes in activation of regional cerebral blood flow 
measured with $\left[{ }^{15} \mathrm{O}\right]$ water and positron emission tomography. J. Cogn. Neurosci. 4, 23-34.

Grady, C. L., McIntosh, A. R., Bookstein, F., Horwitz, B., Rapoport, S. I., and Haxby, J. V. (1998). Age-related changes in regional cerebral blood flow during working memory for faces. Neuroimage 8, 409-425.

Grady, C. L., McIntosh, A. R., Horwitz, B., Maisog, J. M., Ungerleider, L. G., Mentis, M. J., Pietrini, P., Schapiro, M. B., and Haxby, J.V. (1995). Age-related reductions in human recognition memory due to impaired encoding. Science 269, 218-221.

Greenwood, P. M. (2007). Functional plasticity in cognitive aging: review and hypothesis. Neuropsychology 21 , 657-673.

Gutchess, A. H., Welsh, R. C., Hedden, T., Bangert, A., Minear, M., Liu, L. L., and Park, D. C. (2005). Aging and the neural correlates of successful picture encoding: frontal activations compensate for decreased medial-temporal activity. J. Cogn. Neurosci. 17, 84-96.

Hauk, O., Johnsrude, I., and Pulvermuller, F. (2004). Somatotopic representation of action words in human motor and premotor cortex. Neuron 41, 301-307.

Heuninckx, S., Wenderoth, N., and Swinnen, S. P. (2008). Systems neuroplasticity in the aging brain: recruiting additional neural resources for successful motor performance in elderly persons. J. Neurosci. 28, 91-99.

Hillis, A. E., Oh, S., and Ken, L. (2004). Deterioration of naming nouns versus verbs in primary progressive aphasia. Ann. Neurol. 55, 268-275.

Holland, R., Leff, A. P., Josephs, O., Galea, J. M., Desikan, M., Price, C. J., Rothwell, J. C., and Crinion, J. (2011). Speech facilitation by left inferior frontal cortex stimulation. Curr. Biol. 21, 1403-1407.

Jancke, L. (2009). The plastic human brain. Restor. Neurol. Neurosci. 27, 521-538.

Kennedy, K. M., and Raz, N. (2009). Aging white matter and cognition: differential effects of regional variations in diffusion properties on memory, executive functions, and speed. Neuropsychologia 47, 916-927.

Kramer, J. H., Mungas, D., Reed, B. R., Wetzel, M. E., Burnett, M. M., Miller, B. L., Weiner, M. W., and Chui, H. C. (2007). Longitudinal MRI and cognitive change in healthy elderly. Neuropsychology 21, 412-418.

LaBarge, E., Edwards, D., and Knesevich, J. W. (1986). Performance of normal elderly on the Boston Naming Test. Brain Lang. 27, 380-384.

Liljestrom, M., Tarkiainen, A., Parviainen, T., Kujala, J., Numminen, J., Hiltunen, J., Laine, M., and
Salmelin, R. (2008). Perceiving and naming actions and objects. Neuroimage 41, 1132-1141.

Lindenberger, U., and Baltes, P. B. (1994). Sensory functioning and intelligence in old age: a strong connection. Psychol. Aging 9, 339-355.

Logan, J. M., Sanders, A. L., Snyder, A. Z., Morris, J.C., and Buckner, R. L. (2002). Under-recruitment and nonselective recruitment: dissociable neural mechanisms associated with aging. Neuron $33,827-840$

Lustig, C., Snyder, A. Z., Bhakta, M., O’Brien, K. C., McAvoy, M., Raichle, M. E., Morris, J. C., and Buckner, R. L. (2003). Functional deactivations: change with age and dementia of the Alzheimer type. Proc. Natl. Acad. Sci. U.S.A. 100, 14504-14509.

Mackay, A. I., Connor, L. T., Albert, M. L., and Obler, L. K. (2002). Noun and verb retrieval in healthy aging. J. Int. Neuropsychol. Soc. 8, 764-770.

Manenti, R., Cotelli, M., and Miniussi, C. (2011). Successful physiological aging and episodic memory: a brain stimulation study. Behav. Brain Res. 216, 153-158.

Manenti, R., Cotelli, M., Robertson, I. H., and Miniussi, C. (2012). Transcranial brain stimulation studies of episodic memory in young adults, elderly adults and individuals with memory dysfunction: a review. Brain Stimul. 5, 103-109.

McCarthy, R., and Warrington, E. K. (1985). Category specificity in an agrammatic patient: the relative impairment of verb retrieval and comprehension. Neuropsychologia 23, 709-727.

Mevel, K., Chetelat, G., Eustache, F., and Desgranges, B. (2011). The default mode network in healthy aging and Alzheimer's disease. Int. J. Alzheimers Dis. 2011, 535816.

Miceli, G. (1988). A patterns of dissociation in comprehension and production of nouns and verbs. Aphasiology 2, 251-258.

Miceli, G., and Caramazza, A. (1988) Dissociation of inflectional and derivational morphology. Brain Lang. 35, 24-65.

Miceli, G., Silveri, M. C., Villa, G., and Caramazza, A. (1984). On the basis for the agrammatic's difficulty in producing main verbs. Cortex 20, 207-220.

Miller, S. L., Celone, K., DePeau, K., Diamond, E., Dickerson, B. C., Rentz, D., Pihlajamäki, M., and Sperling, R.A. (2008). Age-related memory impairment associated with loss of parietal deactivation but preserved hippocampal activation. Proc. Natl. Acad. Sci. U.S.A. 105, 2181-2186.

Miniussi, C., and Rossini, P. M. (2011). Transcranial magnetic stimulation in cognitive rehabilitation. Neuropsychol. Rehabil. 21, 579-601.

Miniussi, C., Ruzzoli, M., and Walsh, V. (2010). The mechanism of transcranial magnetic stimulation in cognition. Cortex 46, 128-130.

Miozzo, A., Soardi, M., and Cappa, S. F. (1994). Pure anomia with spared action naming due to a left temporal lesion. Neuropsychologia 32, 1101-1109.

Mitchell, D. B. (1989). How many memory systems? Evidence from aging. J. Exp. Psychol. Learn Mem. Cogn. 15 31-49.

Morrison, C. M., Hirsh, K. W., and Duggan, G. B. (2003). Age of acquisition, ageing, and verb production: normative and experimental data. $Q$. J. Exp. Psychol. A 56, 705-730.

Mortensen, L., Meyer, A. S., and Humphreys, G.W. (2006). Age-related effects on speech production: a review. Lang. Cogn. Process. 21, 238-290.

Mottaghy, F. M., Hungs, M., Brugmann, M., Sparing, R., Boroojerdi, B. Foltys, H., Huber, W., and Töpper, R. (1999). Facilitation of picture naming after repetitive transcranial magnetic stimulation. Neurology 53 , 1806-1812.

Mottaghy, F. M., Sparing, R., and Topper, R. (2006). Enhancing picture naming with transcranial magnetic stimulation. Behav. Neurol. 17, 177-186.

Muslimovic, D., Post, B., Speelman, J. D., and Schmand, B. (2005). Cognitive profile of patients with newly diagnosed Parkinson disease. Neurology 65, 1239-1245.

Nicholas, M., Obler, L., Albert, M., and Goodglass, H. (1985). Lexical retrieval in healthy aging. Cortex 21, 595-606.

Nitsche, M.A., Cohen, L. G., Wassermann, E. M., Priori, A., Lang, N., Antal, A., Paulus, W., Hummel, F., Boggio, P. S., Fregni, F., and Pascual-Leone, A. (2008). Transcranial direct current stimulation: state of the art 2008. Brain Stimul. 1, 206-223.

Park, D. C., Polk, T. A., Park, R., Minear, M., Savage, A., and Smith, M. R. (2004). Aging reduces neural specialization in ventral visual cortex. Proc. Natl. Acad. Sci. U.S.A. 101, 13091-13095.

Park, D. C., and Reuter-Lorenz, P. (2009). The adaptive brain: aging and neurocognitive scaffolding. Annu. Rev Psychol. 60, 173-196.

Peran, P., Cardebat, D., Cherubini, A., Piras, F., Luccichenti, G., Peppe, A., Caltagirone, C., Rascol, O., Démonet, J. F., and Sabatini, U. (2009). Object naming and action-verb generation in Parkinson's disease: a fMRI study. Cortex 45, 960-971.

Perani, D., Cappa, S. F., Schnur, T., Tettamanti, M., Collina, S., Rosa, M M., and Fazio, F. (1999). The neural correlates of verb and noun processing. A PET study. Brain 122 (Pt 12), 2337-2344.

Persson, J., Lustig, C., Nelson, J. K., and Reuter-Lorenz, P. A. (2007). Age differences in deactivation: a link to cognitive control? J. Cogn. Neurosci. 19, 1021-1032.

Pobric, G., Jefferies, E., and Ralph, M. A. (2007). Anterior temporal lobes mediate semantic representation: mimicking semantic dementia by using rTMS in normal participants. Proc. Natl. Acad. Sci. U.S.A. 104, 20137-20141.

Price, C. J., Devlin, J. T., Moore, C. J., Morton, C., and Laird, A. R. (2005). Meta-analyses of object naming: effect of baseline. Hum. Brain Mapp. $25,70-82$.

Pulvermuller, F. (2003). The Neuroscience of Language: On Brain Circuits of Words and Serial Order. Cambridge: Cambridge University Press.

Pulvermuller, F., Cook, C., and Hauk, O. (2012). Inflection in action: semantic motor system activation to noun- and verb-containing phrases is modulated by the presence of overt grammatical markers. Neuroimage 60, 1367-1379.

Pulvermuller, F., Lutzenberger, W., and Preissl, H. (1999). Nouns and verbs in the intact brain: evidence from event-related potentials and highfrequency cortical responses. Cereb. Cortex 9, 497-506.

Raichle, M.E., MacLeod,A.M., Snyder, A. Z., Powers, W. J., Gusnard, D. A., and Shulman, G. L. (2001). A default mode of brain function. Proc. Natl. Acad. Sci. U.S.A. 98, 676-682.

Rajah, M. N., and D'Esposito, M. (2005). Region-specific changes in prefrontal function with age: a review of PET and fMRI studies on working and episodic memory. Brain 128, 1964-1983.

Raz, N., Lindenberger, U., Rodrigue, K. M., Kennedy, K. M., Head, D., Williamson, A., Dahle, C., Gerstorf, D., and Acker, J.D. (2005). Regional brain changes in aging healthy adults: general trends, individual differences and modifiers. Cereb. Cortex 15, 1676-1689.

Reinert, G. (1970). "Comparative factor analytic studies of intelligence throughout the life span," in Lifespan Developmental Psychology: Research and Theory, eds L. R. Goulet and P. B. Baltes (New York: Academic Press), 476-484.

Resnick, S. M., Pham, D. L., Kraut, M. A., Zonderman, A. B., and Davatzikos, C. (2003). Longitudinal magnetic resonance imaging studies of older adults: a shrinking brain. J. Neurosci. 23, 3295-3301.

Reuter-Lorenz, P. A., and Lustig, C. (2005). Brain aging: reorganizing discoveries about the aging mind. Curr. Opin. Neurobiol. 15, 245-251. 
Reuter-Lorenz, P. A., and Park, D. C. (2010). Human neuroscience and the aging mind: a new look at old problems. J. Gerontol. B Psychol. Sci. Soc. Sci. 65, 405-415.

Rodriguez-Oroz, M. C., Jahanshahi, M., Krack, P., Litvan, I., Macias, R., Bezard, E., and Obeso, J.A. (2009). Initial clinical manifestations of Parkinson's disease: features and pathophysiological mechanisms. Lancet Neurol. 8, 1128-1139.

Ross, T. P., Lichtenberg, P. A., and Christensen, B. K. (1995). Normative data on the boston naming test for elderly adults in a demographically diverse medical sample. Clin. Neuropsychol. 9, 321-325.

Rossi, S., Cappa, S. F., Babiloni, C., Pasqualetti, P., Miniussi, C., Carducci, F., Babiloni, F., and Rossini, P. M. (2001). Prefrontal cortex in long-term memory: an "interference" approach using magnetic stimulation. Nat. Neurosci. 4, 948-952.

Rypma, B., and D'Esposito, M. (2000). Isolating the neural mechanisms of age-related changes in human working memory. Nat. Neurosci. 3, 509-515.

Salthouse, T. (2010). Major Issues in Cognitive Aging. New York: Oxford University Press.

Sandrini, M., Umilta, C., and Rusconi, E. (2011). The use of transcranial magnetic stimulation in cognitive neuroscience: a new synthesis of methodological issues. Neurosci. Biobehav. Rev. 35, 516-536.

Schuhmann, T., Schiller, N. O., Goebel, R., and Sack, A. T. (2009). The temporal characteristics of functional activation in Broca's area during overt picture naming. Cortex 45, 1111-1116.

Schuhmann, T., Schiller, N. O., Goebel, R., and Sack, A. T. (2012). Speaking of which: dissecting the neurocognitive network of language production in picture naming. Cereb. Cortex 22, 701-709.

Schwartz, B. L., and Metcalfe, J. (2011). Tip-of-the-tongue (TOT) states: retrieval, behavior, and experience. Mem. Cognit. 39, 737-749.

Shafto, M. A., Burke, D. M., Stamatakis, E. A., Tam, P. P., and Tyler, L. K. (2007). On the tip-of-the-tongue: neural correlates of increased word-finding failures in normal aging. J. Cogn. Neurosci. 19, 2060-2070.
Shafto, M. A., Stamatakis, E. A., Tam, P. P. and Tyler, L. K. (2009). Word retrieva failures in old age: the relationship between structure and function. $J$. Cogn. Neurosci. 22, 1530-1540.

Shapiro, K., and Caramazza, A. (2003a). Grammatical processing of nouns and verbs in left frontal cortex? Neuropsychologia 41, 1189-1198.

Shapiro, K., and Caramazza, A. (2003b). The representation of grammatical categories in the brain. Trends Cogn. Sci. (Regul. Ed.) 7, 201-206.

Shapiro, K.A., Moo, L. R., and Caramazza, A. (2006). Cortical signatures of noun and verb production. Proc. Natl. Acad. Sci. U.S.A. 103, 1644-1649.

Silveri, M. C., and Ciccarelli, N. (2007). Naming of grammatical classes in frontotemporal dementias: linguistic and non linguistic factors contribute to noun-verb dissociation. Behav. Neurol. 18, 197-206.

Small, S. A., Tsai, W. Y., DeLaPaz, R., Mayeux, R., and Stern, Y. (2002). Imaging hippocampal function across the human life span: is memory decline normal or not? Ann. Neurol. 51, 290-295.

Sowell, E. R., Peterson, B. S., Thompson, P. M., Welcome, S. E., Henkenius, A. L., and Toga, A. W. (2003). Mapping cortical change across the human life span. Nat. Neurosci. 6, 309-315.

Sparing, R., Dafotakis, M., Meister, I. G., Thirugnanasambandam, N., and Fink, G. R. (2008). Enhancing language performance with non-invasive brain stimulation - a transcranial direct current stimulation study in healthy humans. Neuropsychologia 46, 261-268.

Sparing, R., Mottaghy, F. M., Hungs, M. Brugmann, M., Foltys, H., Huber, W., and Töpper, R. (2001). Repetitive transcranial magnetic stimulation effects on language function depend on the stimulation parameters. J. Clin. Neurophysiol. 18, 326-330.

Stamatakis, E. A., Marslen-Wilson, W. D., Tyler, L. K., and Fletcher, P. C. (2005). Cingulate control of fronto-temporal integration reflects linguistic demands: a three-way interaction in functional connectivity. Neuroimage 28, 115-121.

Stamatakis, E. A., Shafto, M. A., Williams, G., Tam, P., and Tyler, L. K. (2011). White matter changes and word find- ing failures with increasing age. PLoS ONE 6, e14496. doi: 10.1371/journal. pone.0014496

Stebbins, G. T., Carrillo, M. C., Dorfman, J., Dirksen, C., Desmond, J. E., Turner, D. A., Bennett, D. A., Wilson, R. S., Glover, G., and Gabrieli, J. D. (2002). Aging effects on memory encoding in the frontal lobes. Psychol. Aging $17,44-55$.

Szekely, A., D’Amico, S., Devescovi, A. Federmeier, K., Herron, D., Iyer, G. Jacobsen, T., Arévalo, A. L., Vargha, A. and Bates, E. (2005). Timed action and object naming. Cortex 41, 7-25.

Tettamanti, M., Buccino, G., Saccuman, M. C., Gallese, V., Danna, M., Scifo, P., Fazio, F., Rizzolatti, G., Cappa, S. F., and Perani, D. (2005). Listening to action-related sentences activates fronto-parietal motor circuits. J. Cogn Neurosci. 17, 273-281.

Thomas, J. C., Fozard, J. L., and Waugh, N. C. (1977). Age-related differences in naming latency. Am. J. Psychol. 90 499-509.

Topper, R., Mottaghy, F. M., Brugmann, M., Noth, J., and Huber, W. (1998). Facilitation of picture naming by focal transcranial magnetic stimulation of Wernicke's area. Exp. Brain Res. 121, 371-378.

Tyler, L. K., Shafto, M. A., Randall, B. Wright, P., Marslen-Wilson, W.D., and Stamatakis, E. A. (2010). Preserving syntactic processing across the adult life span: the modulation of the frontotemporal language system in the context of age-related atrophy. Cereb. Cortex 20, 352-364.

Verhaeghen, P. (2003). Aging and vocabulary scores: a meta-analysis. Psychol. Aging 18, 332-339.

Vigliocco, G., Vinson, D. P., Druks, J., Barber, H., and Cappa, S. F. (2011). Nouns and verbs in the brain: a review of behavioural, electrophysiological, neuropsychological and imaging studies. Neurosci. Biobehav. Rev. 35 , 407-426.

Voss, M. W., Erickson, K. I., Chaddock, L., Prakash, R. S., Colcombe, S. J. Morris, K. S., Doerksen, S., Hu, L. McAuley, E., and Kramer, A. F. (2008). Dedifferentiation in the visual cortex: an fMRI investigation of individual differences in older adults. Brain Res. 1244, 121-131.
West, M. J., Coleman, P. D., Flood, D. G., and Troncoso, J.C. (1994). Differences in the pattern of hippocampal neuronal loss in normal ageing and Alzheimer's disease. Lancet 344 , 769-772.

Wierenga, C. E., Benjamin, M., Gopinath, K., Perlstein, W. M., Leonard, C. M., Rothi, L. J., Conway, T., Cato, M. A., Briggs, R., and Crosson, B. (2008). Age-related changes in word retrieval: role of bilateral frontal and subcortical networks. Neurobiol. Aging 29, 436-451.

Wirth, M., Rahman, R. A., Kuenecke, J., Koenig, T., Horn, H., Sommer, W., and Dierks, T. (2011). Effects of transcranial direct current stimulation (tDCS) on behaviour and electrophysiology of language production. Neuropsychologia 49, 3989-3998.

Zgaljardic, D. J., Borod, J. C., Foldi, N. S., Mattis, P. J., Gordon, M. F., Feigin, A., and Eidelberg, D. (2006). An examination of executive dysfunction associated with frontostriatal circuitry in Parkinson's disease. J. Clin. Exp. Neuropsychol. 28, 1127-1144.

Zollig, J., and Eschen,A. (2009). Measuring compensation and its plasticity across the lifespan. Restor. Neurol. Neurosci. 27, 421-433.

Conflict of Interest Statement: The authors declare that the research was conducted in the absence of any commercial or financial relationships that could be construed as a potential conflict of interest.

Received: 11 June 2012; paper pending published: 25 June 2012; accepted: 27 July 2012; published online: 20 August 2012.

Citation: Cotelli M, Manenti R, Brambilla $M$, Zanetti $O$ and Miniussi $C$ (2012) Naming ability changes in physiological and pathological aging. Front. Neurosci. 6:120 doi: 10.3389/fnins.2012.00120

Copyright (c) 2012 Cotelli, Manenti, Brambilla, Zanetti and Miniussi. This is an open-access article distributed under the terms of the Creative Commons Attribution License, which permits use, distribution and reproduction in other forums, provided the original authors and source are credited and subject to any copyright notices concerning any third-party graphics etc. 